\title{
Article
}

\section{Dual-Route Hydrogenation of the Graphene/Ni Interface}

Daniel Lizzit, Mario Italo Trioni, Luca Bignardi, Paolo Lacovig, Silvano Lizzit, Rocco Martinazzo, and Rosanna Larciprete

ACS Nano, Just Accepted Manuscript • DOI: 10.1021/acsnano.8b07996 • Publication Date (Web): 11 Jan 2019

Downloaded from http://pubs.acs.org on January 21, 2019

\section{Just Accepted}

"Just Accepted" manuscripts have been peer-reviewed and accepted for publication. They are posted online prior to technical editing, formatting for publication and author proofing. The American Chemical Society provides "Just Accepted" as a service to the research community to expedite the dissemination of scientific material as soon as possible after acceptance. "Just Accepted" manuscripts appear in full in PDF format accompanied by an HTML abstract. "Just Accepted" manuscripts have been fully peer reviewed, but should not be considered the official version of record. They are citable by the Digital Object Identifier (DOI®). "Just Accepted" is an optional service offered to authors. Therefore, the "Just Accepted" Web site may not include all articles that will be published in the journal. After a manuscript is technically edited and formatted, it will be removed from the "Just Accepted" Web site and published as an ASAP article. Note that technical editing may introduce minor changes to the manuscript text and/or graphics which could affect content, and all legal disclaimers and ethical guidelines that apply to the journal pertain. ACS cannot be held responsible for errors or consequences arising from the use of information contained in these "Just Accepted" manuscripts. 
Dual-Route Hydrogenation of the Graphene/Ni

\title{
Interface
}

\author{
Daniel Lizzit, ${ }^{\dagger}$ Mario I. Trioni, ${ }^{\ddagger}$ Luca Bignardi, ${ }^{\dagger}, \|$ Paolo Lacovig, ${ }^{\dagger}$ Silvano \\ Lizzit, ${ }^{*} \dagger$ Rocco Martinazzo, ${ }^{\uparrow}$ and Rosanna Larciprete*,§ \\ $\dagger$ Elettra-Sincrotrone Trieste S.C.p.A., AREA Science Park, S.S. 14 km 163.5, 34149 \\ Trieste, Italy \\ $\ddagger C N R$ - Institute of Molecular Science and Technologies (ISTM), via Golgi 19, 20133 \\ Milano, Italy \\ 【Università degli Studi di Milano, Dip. di Chimica, via Golgi 19, 20133 Milano, Italy \\ $\S C N R$-Institute for Complex Systems (ISC), via dei Taurini 19, 00185 Roma, Italy \\ ||present address: Dep. of Physics, University of Trieste, via Valerio 2, 34127 Trieste, Italy \\ E-mail: silvano.lizzit@elettra.eu; rosanna.larciprete@isc.cnr.it
}

\begin{abstract}
Nanostructured architectures based on graphene/metal interfaces might be efficiently exploited in hydrogen storage due to the attractive capability to provide adsorption sites both at the top side of graphene and at the metal substrate after intercalation. We combined in situ high resolution x-ray photoelectron spectroscopy and scanning tunneling microscopy with theoretical calculations to determine the arrangement of hydrogen atoms at the graphene/ $\mathrm{Ni}(111)$ interface at room temperature. Our results show that at low coverage $\mathrm{H}$ atoms predominantly adsorb as monomers and that chemisorption saturates when $\sim 25 \%$ of the surface is hydrogenated. In parallel, with a much lower rate, $\mathrm{H}$ atoms intercalate below graphene and bind to Ni surface


sites. Intercalation progressively destabilizes the $\mathrm{C}-\mathrm{H}$ bonds and triggers the release of the hydrogen chemisorbed on graphene. Valence band and near edge absorption spectroscopy demonstrate that the graphene layer is fully lifted when the Ni surface is saturated with H. Thermal programmed desorption was used to determine the stability of the hydrogenated interface. Whereas the $\mathrm{H}$ atoms chemisorbed on graphene remain unperturbed over a wide temperature range, the intercalated phase abruptly desorbs 50-100 K above room temperature.

KEYWORDS: graphene, nickel, hydrogenation, storage, intercalation, desorption

Functionalization with hydrogen atoms has been shown to be one of the simplest ways to change the electronic properties of graphene $(\mathrm{Gr})$. In free standing $\mathrm{Gr}$, every $\mathrm{C}$ atom can in principle bind hydrogen up to the formation of graphane, the completely functionalized material. ${ }^{1}$ It has been excellently demonstrated that the formation of $\mathrm{C}-\mathrm{H}$ bonds transforms Gr from a highly conductive semimetal into an insulator ${ }^{2}$ opening a band gap at the Fermi level, ${ }^{3,4}$ and induces specific magnetic ordering. ${ }^{5,6}$ In parallel, due to the high surface-to-weight ratio of Gr, the other big issue inherent to hydrogenation pertains energy storage. Hydrogen accumulation in Gr can be obtained either by chemisorption ${ }^{1,2,7}$ or by physisorption at low temperatures ${ }^{7,8}$ even though only the former method allows for storage stability. ${ }^{9}$ Unfortunately, up to now, in spite of the perspective of reaching the theoretical gravimetric densities ( $8.2 \%$ for graphane), only moderate values of $1-2 \%$ have been obtained at room temperature, ${ }^{10,11}$ mostly because of the high energy barrier for $\mathrm{H}$ chemisorption. Innovative approaches need to be identified to boost the achievements in this field. One route currently under consideration to enhance the yield of hydrogenation is to exploit the structural flexibility of Gr, following the theoretical demonstration that convexity enhances the reactivity of Gr towards H. ${ }^{12}$ Alternatively, architectures including Gr supported on metals might be attractive, since, in principle, these interfaces allow a dual H storage modality, i.e. chemisorption at the top-side ${ }^{3,13-17}$ and some time also at the bottom side of graphene ${ }^{18,19}$ 
and chemisorption at the substrate surface after intercalation, as it has been proven for analogous BN/metals systems. ${ }^{20-22}$ However, the successful development of materials based on the use of $\mathrm{Gr} /$ metal interfaces requires that, for any specific system, the fundamental properties enhancing or limiting $\mathrm{H}$ chemisorption get fully uncovered. The hydrogenation of Gr on transition metals has been investigated for $\mathrm{Gr} / \mathrm{Ni}(111),{ }^{13-15} \mathrm{Gr} / \mathrm{Cu}$ foils, ${ }^{19} \mathrm{Gr} / \mathrm{Pt}(111){ }^{14,23}$ and especially $\operatorname{Gr} / \operatorname{Ir}(111) .{ }^{3,14,16,17,24}$ Usually, hydrogenation of a complete Gr monolayer requires the exposure to $\mathrm{H}$ atoms, since $\mathrm{H}_{2}$ dissociation on $\mathrm{Gr}$, even in the presence of a catalytic substrate, requires at least vibrationally hot molecules. ${ }^{24}$ The ultimate $\mathrm{H}$ coverage is limited by the competition between the adsorption and desorption/abstraction processes and by the elastic energy that accumulates in the $\mathrm{C}$ lattice once puckered by the local $\mathrm{sp}^{3}$ rehybridization of the $\mathrm{C}$ atoms binding hydrogen. Therefore, usually on $\mathrm{Gr} \mathrm{H}$ coverages lower than 0.5 monolayers $\left(\mathrm{ML}_{\mathrm{Gr}}\right)$ are achieved. An additional factor that typically governs the hydrogenation of supported Gr is the interaction with the metal substrate. This aspect has been deeply investigated in the case of $\operatorname{Gr} / \operatorname{Ir}(111), 3,16,17$ where the substrate-induced Gr corrugation modulates periodically the $\mathrm{H}$ coverage in the moiré supercell. In this case, only in the valley regions the close vicinity to the substrate allows the chemisorbed H to be stabilized by the formation of a "graphane-like" structure, where every other C atom binds to a $\mathrm{H}$ atom above and every other to an Ir atom below.

When considering these aspects, the $\mathrm{Gr} / \mathrm{Ni}(111)$ interface appears much more favorable, as the limitations due to the presence of the moiré supercell vanish ${ }^{15}$ due to commensurate relation between the $\mathrm{Gr}$ and $\mathrm{Ni}(111)$ lattices. ${ }^{25}$ Graphene lies on $\mathrm{Ni}(111)$ in two main configurations, energetically comparable, namely the top-fcc (T-FCC) configuration (see Figure 2c), where the $\mathrm{C}$ atoms are located on top of the Ni atoms and above the $f c c$ sites of the substrate surface and the top-bridge (TB) configuration (see Figure 2b), where the non equivalent $\mathrm{C}$ atoms are located in the bridge positions between the top and $f c c$ sites or between the top and $h c p$ sites of the substrate. ${ }^{26}$

According to recent density functional theory (DFT) calculations, ${ }^{27}$ hydrogenation is 
nearly energetically equivalent for the T-FCC and TB configurations, with the difference that for the T-FCC geometry $\mathrm{H}$ bonding to the $\mathrm{C}$ atom in the $f c c$ site is strongly favored, whereas in the other case the top-fcc and top-hcp sites are almost equivalent to each other. Actually, for $\mathrm{Gr} / \mathrm{Ni}(111)$ in the T-FCC geometry a $\mathrm{H}$ coverage of $0.5 \mathrm{ML}_{\mathrm{Gr}}$ was proposed in Ref. 15, corresponding to the full hydrogenation of the Gr sublattice lying on the $f c c$ sites, with every other $\mathrm{C}$ atom bonded to $\mathrm{H}$ and the other bonded to Ni. Differently, other experimental studies of the $\mathrm{H} / \mathrm{Gr} / \mathrm{Ni}(111)$ system found significantly lower $\mathrm{H}$ saturation coverages around $20 \%^{28}$ and $25 \%^{13}$. The controversy between these results together with the peculiar reactivity of the $\mathrm{Gr} / \mathrm{Ni}$ interface, ${ }^{29-32}$ motivated a re-investigation of the behavior of this system when interacting with hydrogen. Therefore we used x-ray photoelectron spectroscopy (XPS) and near edge x-ray absorption fine structure (NEXAFS) spectroscopy to follow the hydrogenation of the $\mathrm{Gr} / \mathrm{Ni}(111)$ interface at room temperature (RT) and determined the configuration of the hydrogenated interface by scanning tunneling microscopy (STM). By taking advantage of the availability of all experimental techniques in the same setup we could determine by STM the surface nanostructure of the same samples characterized by XPS and NEXAFS. In addition DFT calculations were employed to model hydrogen chemisorption and to assign the observed C1s core level shifts (CLSs). We found that $\mathrm{H}$ chemisorption on Gr saturates when the coverage is $0.20-0.25 \mathrm{ML}_{\mathrm{Gr}}$, in close agreement with

previous reports. ${ }^{13,28}$ In parallel, at much lower rate, intercalation occurs, which destabilizes the $\mathrm{H}$ atoms chemisorbed on the top side of graphene. After the prolonged exposure needed to completely lift Gr, the TPD curves show the fast release of the intercalated hydrogen 50-100 K above room temperature.

\section{Results and discussion}

We monitored the hydrogenation of $\mathrm{Gr} / \mathrm{Ni}(111)$ at $\mathrm{RT}$ by measuring the $\mathrm{C} 1 \mathrm{~s}$ core level spectra while dosing the sample with molecular or atomic hydrogen. In the first case we dosed 

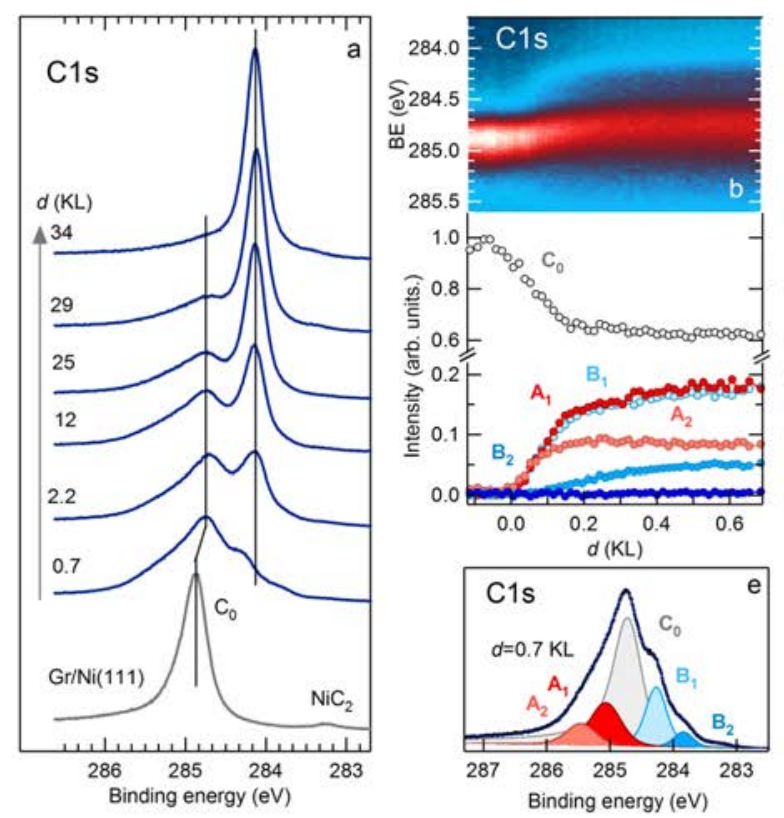

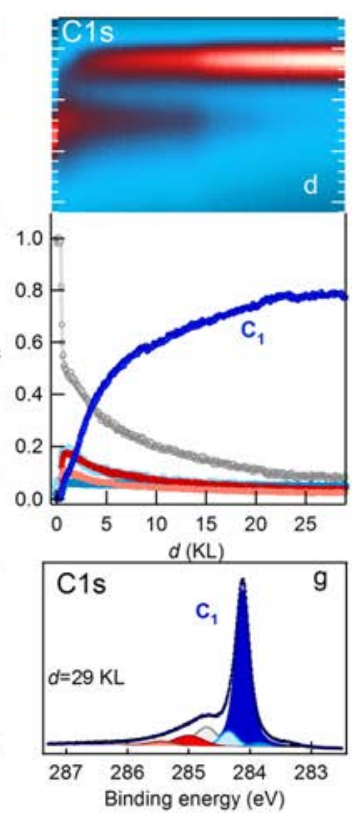

Figure 1: Hydrogen up-take at the $\mathrm{Gr} / \mathrm{Ni}(111)$ interface. a) C1s spectra measured on the $\mathrm{Gr} / \mathrm{Ni}(111)$ surface before (bottom curve) and after the exposure to increasing dose $d$ of hydrogen at room temperature. b, c, d) (top) 2D plots of the C1s total intensity and (bottom) C1s component intensities vs. hydrogen dose. e, f, g) High resolution C1s spectra measured at selected $d$ values, shown with best-fit curves and spectral components.

$\mathrm{H}_{2}$ and the $\mathrm{C} 1 \mathrm{~s}$ spectrum remained completely stable even after a dose of several thousand langmuir $\left(1 \mathrm{~L}=1.33 \times 10^{-6} \mathrm{mbar} \cdot \mathrm{s}\right)$, demonstrating the lack of any hydrogenation. Instead, when hydrogen was dosed through the hot cracker, and then in large part dissociated, the C1s line shape immediately started to change, revealing the strong interaction of the $\mathrm{H}$ atoms with graphene. In the following, the data are reported as a function of the total hydrogen dose $d$, knowing that the fraction $f$ of the dissociated $\mathrm{H}_{2}$ molecules is a fixed value, which can be estimated to be in the range $0.7 \leq f \leq 0.9$ (see Methods). Even if the hydrogen flux contained both molecules and atoms, in the following we refer to it as the atomic $\mathrm{H}$ flux.

The evolution of the C1s spectrum during the exposure to increasing doses of hydrogen can be seen at a glance in Figure 1a. The spectrum measured on the clean $\mathrm{Gr} / \mathrm{Ni}(111)$ surface exhibits a single peak $\mathrm{C}_{0}$ at $284.88 \mathrm{eV}$, due to the graphene layer interacting with the $\mathrm{Ni}$ 
substrate, accompanied by a small feature at $283.25 \mathrm{eV}$ assigned to the $\mathrm{NiC}_{2}$ carbide phase (see also Figure S3). Graphene hydrogenation determines at first the growth of a broad feature at the high binding energy $(\mathrm{BE})$ side of $\mathrm{C}_{0}$ and the appearance of a shoulder at $\sim 284.3 \mathrm{eV}$. Heavier exposures cause the slow growth of a narrow peak at around $284.1 \mathrm{eV}$, that progressively increases and finally tends to include the whole C1s intensity, at the expenses of all the other spectral components.

The details of the chemisorption process were revealed by continuously acquiring the C1s spectra while dosing hydrogen. Figures $1 \mathrm{~b}, 1 \mathrm{c}$ and $1 \mathrm{~d}$ display the $2 \mathrm{D}$ plots of the C1s intensity obtained from the sequences of spectra measured up to doses $d$ of $0.7,2.2$ and $29 \mathrm{KL}$, respectively, whereas Figures 1e, 1f and $1 \mathrm{~g}$ show in each case the resulting high resolution $\mathrm{C} 1 \mathrm{~s}$ spectrum. The analysis of the $\mathrm{C} 1 \mathrm{~s}$ sequences provided the behavior of the different spectral components. Figure $1 \mathrm{~b}$ illustrates that upon exposure to atomic $\mathrm{H}$ the main $\mathrm{C}_{0}$ peak is progressively converted into new components, namely $\mathrm{A}_{1}(284.98 \mathrm{eV}), \mathrm{A}_{2}$ $(285.43 \mathrm{eV}), \mathrm{B}_{1}(284.35 \mathrm{eV})$ and $\mathrm{B}_{2}(283.84 \mathrm{eV})$. The growth of these new components proceeds until a stable configuration is reached and then, at $d \sim 0.6 \mathrm{KL}$, stops indicating the saturation of the $\mathrm{H}$ chemisorption on graphene. Hydrogenation progressively shifts the main $\mathrm{C}_{0}$ component, which at saturation is located $0.2 \mathrm{eV}$ below its BE position on clean $\mathrm{Gr}$ and has about half of its pristine intensity. The BE positions of all $\mathrm{C} 1$ s components and the core level shifts (CLSs), with respect to the $\mathrm{BE}$ of $\mathrm{C}_{0}$ in the clean $\mathrm{Gr} / \mathrm{Ni}(111)$ surface, are listed in Table 1. It is worth noting that, although graphene hydrogenation causes a charge redistribution at the $\mathrm{Gr} / \mathrm{Ni}$ interface ${ }^{27}$ only negligible modifications of the Ni2p spectrum are observed after the exposure to hydrogen (see Figure S2).

In order to assign the C1s components, we calculated the CLSs for several, arbitrarily shaped clusters of one to seven $\mathrm{H}$ atoms on $\mathrm{Gr} / \mathrm{Ni}(111)$. The whole set of CLSs and average H adsorption energies $\left(E_{\text {ads }}\right)$ calculated for the different clusters considered is listed in Table S1. Only the T-FCC geometry of $\mathrm{Gr} / \mathrm{Ni}(111)$ has been scrutinized for extensive hydrogenation since only this arrangement provides a general mechanism for the stabilization of the $\mathrm{H}$ 
Table 1: Binding energy of the C1s components and corresponding core level shifts (CLSs) with respect to the $\mathrm{BE}$ of $\mathrm{C}_{0}$ in the clean $\mathrm{Gr} / \mathrm{Ni}(111)$ surface.

\begin{tabular}{llll}
\hline interface & C1s component & $\begin{array}{l}\mathrm{BE} \\
(\mathrm{eV})\end{array}$ & $\begin{array}{l}\text { CLS } \\
(\mathrm{eV})\end{array}$ \\
\hline $\mathrm{Gr} / \mathrm{Ni}(111)$ & $\mathrm{C}_{0}$ & 284.88 & 0 \\
& $\mathrm{NiC}_{2}$ & 283.25 & -1.63 \\
\hline $\mathrm{H} / \mathrm{Gr} / \mathrm{Ni}(111)$ & $\mathrm{C}_{0}$ & 284.68 & -0.20 \\
& $\mathrm{~A}_{1}$ & 285.05 & +0.17 \\
& $\mathrm{~A}_{2}$ & 285.44 & +0.56 \\
& $\mathrm{~B}_{1}$ & 284.28 & -0.60 \\
& $\mathrm{~B}_{2}$ & 283.84 & -1.04 \\
\hline $\mathrm{Gr} / \mathrm{H} / \mathrm{Ni}(111)$ & $\mathrm{C}_{1}$ & 284.15 & -0.73 \\
\hline
\end{tabular}

adatoms, i.e. a carbon site on a $f c c$ position that is free to move out of the surface plane upon binding the incoming $\mathrm{H}$, and neighboring $\mathrm{C}$ sites in top positions that can get closer to the metal surface and strengthen their bonds with the Ni atoms underneath. This arrangement contributes to make the adsorption of $\mathrm{H}$ monomers on the T-FCC $\operatorname{Gr}\left(E_{\text {ads }}=2.3\right.$ and $1.7 \mathrm{eV}$ in the $f c c$ and top sites, respectively) much more favored than on pristine graphene $\left(E_{\mathrm{ads}} \sim 0.9 \mathrm{eV}^{7}\right)$. For dimers on T-FCC Gr we find that when the second atom adsorbs in meta position the adsorption energy is $0.3-0.4 \mathrm{eV}$ larger than for other neighbor sites (ortho or para) and compares favorably with that of a lonely $\mathrm{H}$ atom in $f c c$ position. For comparison, in the TB geometry the top-fcc and top-hcp adsorption sites are energetically almost identical for adsorption of the first $\mathrm{H}$ atom $(\sim 2.1 \mathrm{eV})$, and for dimers the ortho, meta and para configurations are nearly equivalent, since the corresponding $E_{\text {ads }}$ spread on a range that is only $\sim 0.1 \mathrm{eV}$ wide. ${ }^{27}$ More generally, at any coverage smaller than $0.25 \mathrm{ML}_{\mathrm{Gr}}$ that is of interest in this work (see below), hydrogen adsorption on the TB structure is less stable than on the T-FCC one, by some tenths of eV per $\mathrm{H}$ atom. ${ }^{27}$

Figure 2a compares the experimental C1s spectra measured for $\mathrm{H} / \mathrm{Gr} / \mathrm{Ni}(111)$ dosed with 20, 70 and $700 \mathrm{~L}$ of hydrogen with the calculated CLSs and highlights the main findings of our calculations. The $\mathrm{C}$ atoms binding a $\mathrm{H}$ atom ( $i$ sites, from ipso; orange and red in Figures 2d-2f) contribute at BEs that are positively shifted with respect to pristine graphene, the CLS being higher when they are isolated $\left(i_{0}\right)$, and decreasing when they are second neighbors 
of $n$ other hydrogenated sites $\left(i_{n}\right.$, with $\left.n=1-6\right)$, by approximately $0.2 \mathrm{eV}$ for each neighbor. On the other hand, $\mathrm{C}$ atoms that are first nearest neighbors (i.e., in ortho position) of a hydrogenated C have negative CLSs, that become increasingly large (in magnitude) when increasing the number of neighboring $\mathrm{C}$-H bonds $\left(o_{n}\right.$ sites, where $n=1-3$ is the number of neighboring $\mathrm{C}-\mathrm{H}$ bonds). In particular, the CLSs for the $o_{1}, o_{2}$ and $o_{3}$ are in the intervals $-0.32 /-0.63 \mathrm{eV},-0.86 /-0.98 \mathrm{eV}$ and $-1.30 /-1.44 \mathrm{eV}$, respectively. The CLSs drastically reduce to $-0.1 /-0.2 \mathrm{eV}$ for $\mathrm{C}$ atoms that are only second or third neighbors of $\mathrm{C}-\mathrm{H}$ bonds. The similarity of the CLSs calculated for the several structures of rather different size and shape considered does not allow to exclude or single out any of them. Rather, the coexistence of several configurations seems more plausible and in line with previous observations on other Gr/metal systems. ${ }^{19}$

On the basis of the DFT calculations we conclude that the component $\mathrm{A}_{2}$ is due to the $i_{n}$ sites of isolated $\mathrm{H}$ monomers $\left(i_{0}\right)$ and dimers $\left(i_{1}\right)$, in agreement with the $\mathrm{C} 1$ s spectrum measured at $d=20 \mathrm{~L}$ (Figure $2 \mathrm{a}$ ) showing only the $\mathrm{A}_{2}$ and $\mathrm{B}_{1}$ components besides $\mathrm{C}_{0}$. Monomers and dimers exhibit the lowest stability and, as it will be shown below, at a surface temperature of $\sim 450 \mathrm{~K}$ mostly desorb and/or join larger clusters. According to the calculated CLSs, $\mathrm{A}_{1}$ is assigned to $i_{n}$ sites in $\mathrm{H}$ trimers or larger clusters, whereas $\mathrm{B}_{1}$ and $\mathrm{B}_{2}$ represent the sites that are first neighbor of one or two $\left(o_{1}\right.$ and $\left.o_{2}\right)$ and three $\left(o_{3}\right) \mathrm{C}-\mathrm{H}$ bonds, respectively. In the $\mathrm{C} 1 \mathrm{~s}$ spectra of Figure $2 \mathrm{a}$ the $\mathrm{BE}$ of the component $\mathrm{B}_{1}$ decreases slightly with increasing coverage due to the rising $o_{2} / o_{1}$ ratio. Note that the contribution of each site to the $\mathrm{C} 1 \mathrm{~s}$ spectrum depends on both size and shape of the cluster (e.g. there exist seven $o_{1}$ sites in the $5 \mathrm{H}$ cluster of Figure $2 \mathrm{f}$, but only three $o_{n}$ with $n>1$ ). This attribution is in full agreement with the evolution of the C1s spectrum displayed in Figure 2a, showing that $A_{1}$ and $B_{1}$ become dominant at large hydrogen dose and $B_{2}$ acquires a sizable intensity only when the clusters grow in size. The limited BE shift calculated for C atoms second and third neighbors of the $\mathrm{C}-\mathrm{H}$ bonds reflects into the $\mathrm{BE}$ shift of $-0.1 /-0.2 \mathrm{eV}$ exhibited by $\mathrm{C}_{0}$ after large $\mathrm{H}$ doses. 
Figure 2: DFT C1s core level shifts of hydrogenated Gr on Ni(111). a) DFT C1s core level shifts calculated for TB (diamonds) and T-FCC (triangles) Gr/Ni(111) hydrogenated with $\mathrm{H}$ clusters of increasing sizes (cfr. Table S1) compared with the experimental C1s spectra measured for the $\mathrm{Gr} / \mathrm{Ni}(111)$ dosed with $d=20,70$ and $700 \mathrm{~L}$ of hydrogen. The black symbols indicate the BEs of pristine graphene. The CLSs are calculated with respect to the $\mathrm{BE}$ of $\mathrm{C}$ atoms in the top position in T-FCC graphene. b) TB and c) T-FCC geometries of $\mathrm{Gr} / \mathrm{Ni}(111)$; in b) 1 and 2 indicate the top-fcc and the top-hcp sites, respectively. In c) $\mathrm{O}, \mathrm{M}$ and $\mathrm{P}$ indicate ortho, meta and para sites relative to the $\mathrm{C}$ atom depicted in yellow. $\mathrm{d}-\mathrm{e})$ Schemes of the d) $1 \mathrm{H}$ and $2 \mathrm{H}$, e) $3 \mathrm{H}$ and f) $5 \mathrm{H}$ clusters on the T-FCC graphene. Orange and red circles represent $i_{n}$ sites, i.e. $\mathrm{C}$ atoms bonded to $\mathrm{H}$, that are isolated $\left(1 \mathrm{H}, i_{0}\right)$ or second neighbors of other hydrogenated sites $\left(i_{n}, n=1-6\right)$. Light, medium and dark cyan circles represent $o_{1}, o_{2}$ and $o_{3}$ sites, respectively, i.e. C atoms that are first neighbors of 1 , 2 or $3 \mathrm{C}-\mathrm{H}$ bonds, respectively. 
With these assignments the $\mathrm{C} 1$ s spectrum reveals that at RT not more than one quarter of the $\mathrm{C}$ atoms form $\mathrm{C}-\mathrm{H}$ bonds (those contributing to $\mathrm{A}_{1}$ and $\mathrm{A}_{2}$ ), implying that hydrogen chemisorption saturates at $0.20-0.25 \mathrm{ML}_{G r}$, a coverage significantly smaller than the value of $0.5 \mathrm{ML}_{\mathrm{Gr}}$ quoted in Ref. 15 and suggestive of graphone. These findings are compatible with previous helium scattering measurements reporting hydrogen saturation of graphene at a $\mathrm{H} / \mathrm{C}$ ratio of $\sim 20 \% .^{28}$
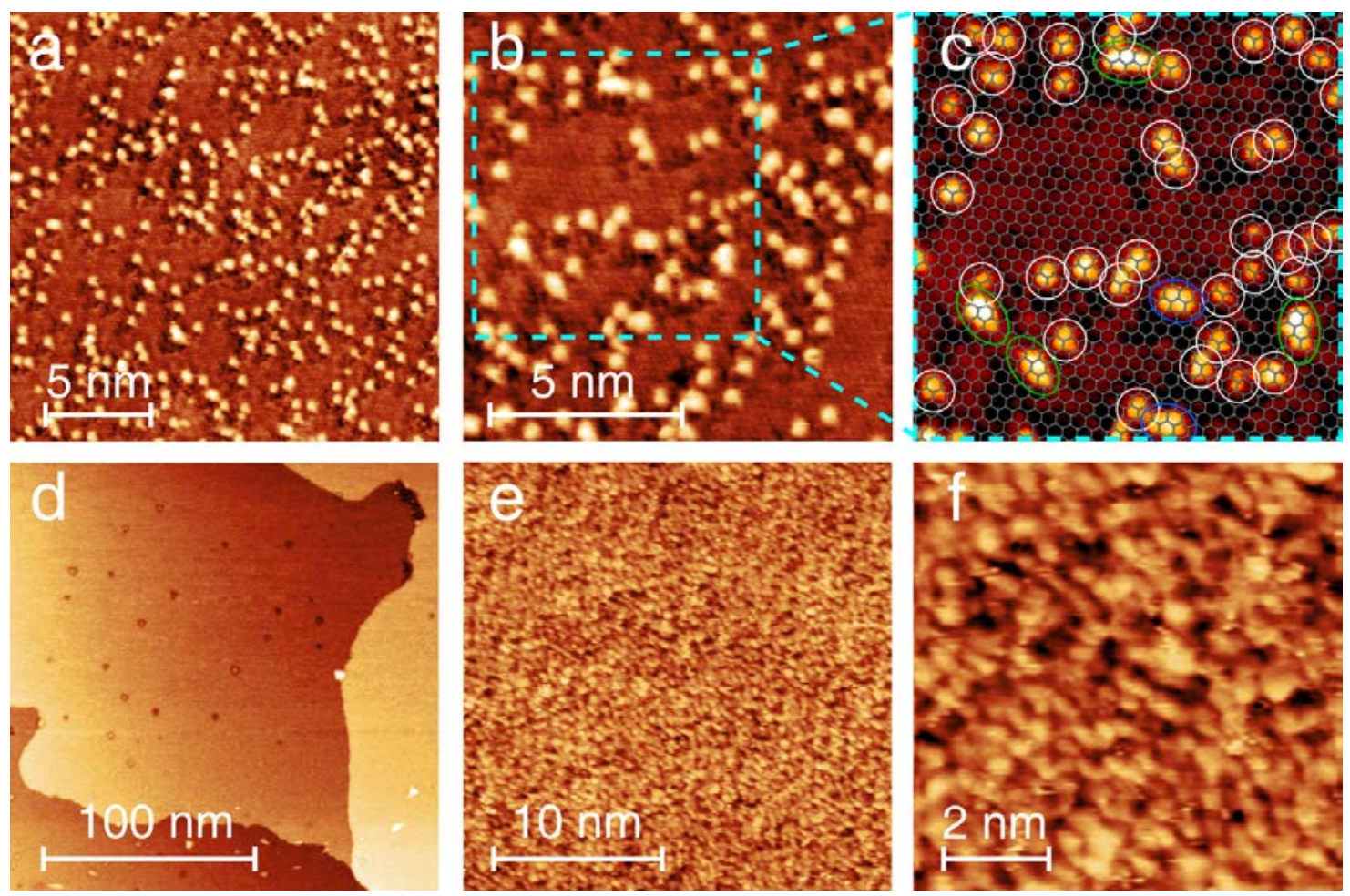

Figure 3: Scanning tunneling microscopy of hydrogenated Gr/Ni(111). STM images taken on the $\mathrm{Gr} / \mathrm{Ni}(111)$ surface dosed with (a-c) $20 \mathrm{~L}(0.940 \mathrm{~V}, 0.05 \mathrm{nA})$ and (d-f) $0.7 \mathrm{KL}$ of hydrogen $(-0.330 \mathrm{~V},-0.11 \mathrm{nA})$. In panel c) a mesh reproducing the graphene lattice has been superimposed on the image; the white and blue circles and the green ellipses enclose $\mathrm{H}$ clusters classified according to their size and shape (see text for details).

To further investigate the hydrogen chemisorption on $\mathrm{Gr} / \mathrm{Ni}(111)$, we performed STM measurements. Figures 3a-3c and 3d-3f display the images taken on the sample surface exposed to $d=20$ and $700 \mathrm{~L}$ of hydrogen, respectively. Figure 3a shows an apparently random distribution of bright protrusion on graphene, whose honeycomb lattice can be better observed in the H-free areas of Figure 3b. As can be seen in Figure 3c, where the honeycomb 
grid has been superimposed on top of the STM image, the protrusions are mostly small structures (white circles) accompanied by few elongated (green ellipses) and rare round-like (blue circles) features. By comparison with the STM images taken on hydrogenated graphite and $\mathrm{Gr} / \mathrm{SiC}(0001)$ surfaces ${ }^{33,34}$ and simulated for $\mathrm{H} / \mathrm{Gr},{ }^{35}$ the smallest features are assigned to $\mathrm{H}$ monomers. They exhibit the characteristic threefold symmetry protruding towards the para sites ${ }^{35}$ and appear in large part located on the same graphene sublattice, that is consistent with the T-FCC geometry of $\mathrm{Gr} / \mathrm{Ni}(111)$, where the $\mathrm{H}$ atoms bind preferably to the $f c c$ sites (Figure 2f), as opposed to the TB configuration, where the adsorption on both sublattices is equally probable. The elongated structures plausibly are $\mathrm{H}$ dimers. The image resolution does not allow to determine their internal structure, although meta-dimers would be slightly favored on T-FCC Gr with respect to the other configurations, ${ }^{27}$ at variance with hydrogenated graphite where the two $\mathrm{H}$ atoms preferentially adsorb on the different sublattices forming ortho- and para-dimers. The rare round-like features (blue circles) can be tentatively assigned to $\mathrm{H}$ trimers. It is worth noting that in comparison to graphite and $\mathrm{Gr} / \mathrm{SiC}(0001)$ surfaces hydrogenated at similar or even lower coverage, where mostly dimers or larger clusters are observed, ${ }^{33,34,36}$ in this case $\mathrm{H}$ atoms adsorb preferentially as monomers, in agreement with the high stability of this arrangement on the $\mathrm{Gr} / \mathrm{Ni}(111)$ surface. Figures 3d-3f show the graphene surface after a hydrogen dose of $700 \mathrm{~L}$ that, according to Figure 1, corresponds to the saturation of the chemisorbed phase. Hydrogen adatoms appears as small features coexisting with larger clusters, uniformily covering the surface terraces without any evident ordering. Although graphene cannot be observed, XPS and TPD measurements indicate that for this surface the $\mathrm{H}$ coverage does not exceed $0.25 \mathrm{ML}_{\mathrm{Gr}}$.

Figures $1 \mathrm{c}$ and $1 \mathrm{~d}$ show that, if the saturated $\mathrm{H} / \mathrm{Gr} / \mathrm{Ni}(111)$ surface is exposed to additional atomic hydrogen, the $\mathrm{C}_{1}$ component appears and progressively rises subtracting intensity to all other components. As a matter of fact, the C1s spectrum measured at $d=34 \mathrm{KL}$ (see Figure 1a) consists almost exclusively of $\mathrm{C}_{1}$. The low rate of conversion of every $\mathrm{C} 1 \mathrm{~s}$ component into $\mathrm{C}_{1}$, together with the $\mathrm{C}_{1} \mathrm{BE}$ itself matching that of graphene decoupled from 
Figure 4: STM images of partially $\mathbf{H}$ intercalated $\mathbf{G r} / \mathbf{N i}(111)$. a) Large scale image $(0.574 \mathrm{~V}, 0.14 \mathrm{nA})$ taken on the sample dosed with $2.2 \mathrm{KL}$ of hydrogen showing bright (covered by chemisorbed hydrogen) and dark (lifted by intercalated hydrogen) regions that extend over the $\mathrm{Ni}(111)$ terraces. b-c) High resolution images of the areas framed in different colors in a) showing b) $(0.251 \mathrm{~V}, 1.22 \mathrm{nA})$ the $\mathrm{H}$ clusters and c) $(1.358 \mathrm{~V}, 0.12 \mathrm{nA})$ the atomically resolved Gr lattice.

the Ni substrate, ${ }^{13,37,38}$ suggest the occurrence of a slow, but continuous, H intercalation. ${ }^{39}$ A direct way to prove the diffusion of $\mathrm{H}$ below $\mathrm{Gr}$ would be to reveal the formation of $\mathrm{Ni}-\mathrm{H}$ bonds by monitoring the $\mathrm{Ni}$ core level spectra, but, due to the scarce sensitivity of these spectral features to $\mathrm{H}$ chemisorption (see Figure S2), this approach cannot be convincingly pursued. However, unambiguous indications for the occurrence of $\mathrm{H}$ intercalation below $\mathrm{Gr}$ are provided by the STM images taken after the exposure to $2.2 \mathrm{KL}$ of hydrogen, and shown in Figure 4, coupled with the corresponding XPS results reported in Figure 1f. Fully hydrogenated and fully dehydrogenated regions on the same and on contiguous terraces are 

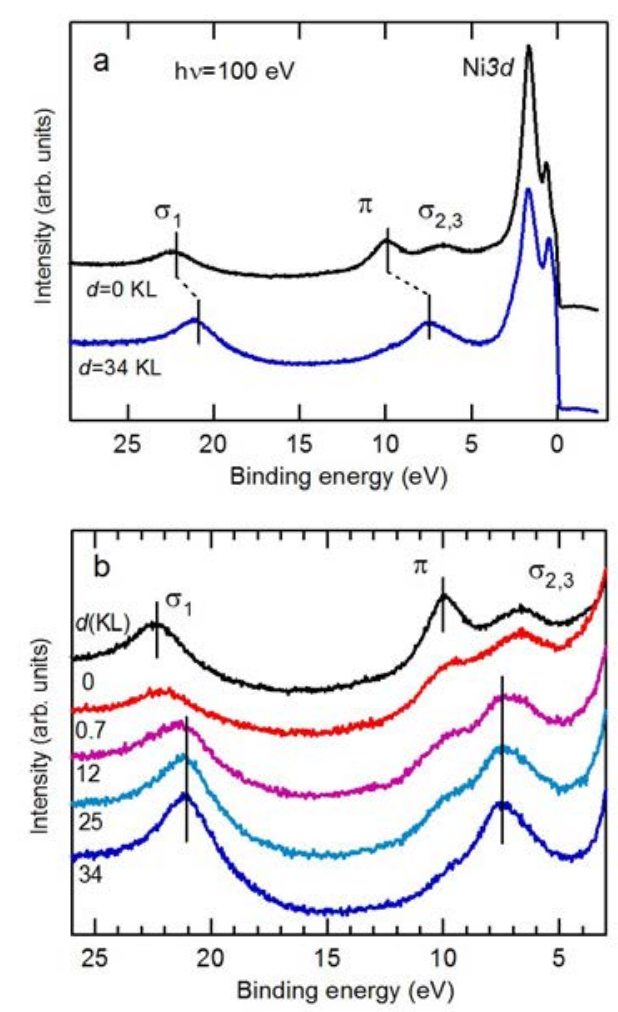

Figure 5: Valence band of hydrogenated $\mathbf{G r} / \mathrm{Ni}(\mathbf{1 1 1})$. a) Valence band spectra measured at normal emission angle and at photon energy of $100 \mathrm{eV}$ on the $\mathrm{Gr} / \mathrm{Ni}(111)$ surface before and after the exposure to $34 \mathrm{KL}$ of hydrogen. b) Evolution of the $\sigma_{1}$ and $\pi$ bands of graphene with increasing hydrogen dose.

The possibility to decouple the entire Gr layer is confirmed by the evolution of valence 
band and NEXAFS spectra shown in Figure 5 and Figure 6. Figure 5 shows the VB spectrum measured at normal emission with photon energy of $100 \mathrm{eV}$ on the bare $\mathrm{Gr} / \mathrm{Ni}(111)$ surface and its evolution with increasing $\mathrm{H}$ coverage. The spectrum measured on the clean surface exhibits the $\mathrm{Ni} d$-states peaked at 0.6 and $1.7 \mathrm{eV}$ and the $\sigma_{2-3}(6.5 \mathrm{eV}), \pi(10.0 \mathrm{eV})$ and $\sigma_{1}(22.4 \mathrm{eV})$ states of the graphene coupled to the Ni substrate. ${ }^{40}$ Exposure to $0.7 \mathrm{KL}$ of hydrogen causes attenuation and broadening of these features, whereas net shifts of the $\sigma_{1}$ and $\pi$ bands are clearly observed after heavier hydrogenation. At $d=34 \mathrm{KL}$ the features appearing at 7.5 and $21 \mathrm{eV}$ arise from the typical $\pi$ and $\sigma_{1}$ states of nearly free-standing graphene. The shift of $\sim 2 \mathrm{eV}$ with respect to the clean $\mathrm{Gr} / \mathrm{Ni}(111)$ is similar to that observed when decoupling Gr from the Ni substrate by Au intercalation. ${ }^{40}$
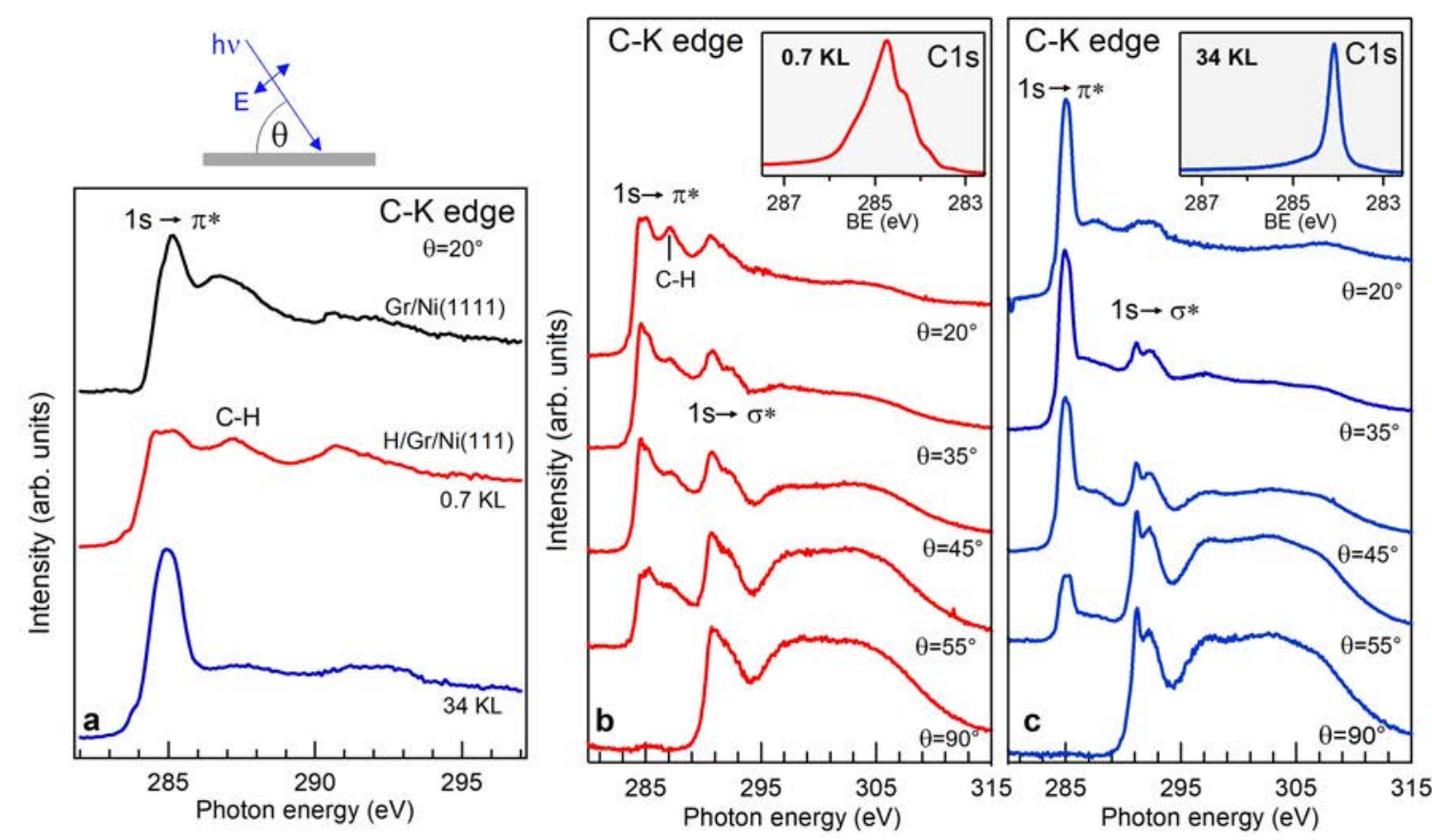

Figure 6: NEXAFS spectroscopy of hydrogenated Gr/Ni(111). a) C-K edge NEXAFS spectra measured at $\theta=20^{\circ}$ on the clean $\mathrm{Gr} / \mathrm{Ni}(111)$ surface and after the exposure to 0.7 and $34 \mathrm{KL}$ of hydrogen. $\theta$ is the angle between the direction of the x-ray beam and the sample surface and is defined in the left-top panel. b-c) C-K edge NEXAFS spectra measured on the $\mathrm{Gr} / \mathrm{Ni}(111)$ surface exposed to b) $d=0.7 \mathrm{KL}$ and c) $d=34 \mathrm{KL}$ of hydrogen as a function of $\theta$. The corresponding $\mathrm{C} 1 \mathrm{~s}$ spectra are shown in the insets. In all figures the NEXAFS spectra are vertically shifted for clarity. 
Further indications for full Gr layer lifting are provided by the NEXAFS measurements. When performed as a function of the angle between the photon beam and the sample surface, this technique probes the direction of the unoccupied orbital where the core electron is excited, as the resonance intensity is maximal when the orbital is parallel to the electric field $E$ of the photon beam. ${ }^{41}$ Figure 6a compares the C-K edge NEXAFS spectra measured on $\mathrm{Gr} / \mathrm{Ni}(111)$ as a function of the hydrogen dose, taken in grazing incidence configuration at $\theta=20^{\circ}$, being $\theta$ the angle between $E$ and the normal to the sample surface (or, equivalently, that between the direction of the x-ray beam and the sample surface). The spectrum measured on the clean $\mathrm{Gr} / \mathrm{Ni}(111)$ shows two features at 285 and $286.5 \mathrm{eV}$ in the $1 \mathrm{~s} \rightarrow \pi^{*}$ spectral region, due to the transition of the $\mathrm{C} 1 \mathrm{~s}$ electrons into two unoccupied C-Ni hybridized states above the Fermi level. ${ }^{42}$ At $d=0.7 \mathrm{KL}$, graphene hydrogenation is revealed by the feature appearing at $287.2 \mathrm{eV}$, which is associated with $\mathrm{C}-\mathrm{H}$ bonds. ${ }^{14,43,44}$ Hydrogenation is accompanied by a partial quenching of the $\pi^{*}$ resonance, ${ }^{43}$ and is also indirectly signaled by the intensity increase in the so called "pre-edge" region at $\sim 284.3 \mathrm{eV},{ }^{14,43}$ resulting from the enhanced interaction with the Ni substrate. At this hydrogenation stage the NEXAFS spectra measured as a function of $\theta$ (Figure 6b) manifest the marked dichroism usually observed for $\mathrm{Gr} / \mathrm{Ni}(111)$ samples, ${ }^{37,42}$ with the $\pi^{*}$ resonance dominating for grazing incidence angles and the $\sigma^{*}$ resonance emerging when $\theta$ approaches the normal incidence configuration. The angular dependence of the $\mathrm{C}-\mathrm{H}$ peak intensity also proves that the $\mathrm{C}-\mathrm{H}$ bonds are oriented perpendicularly to the graphene plane. ${ }^{14}$ When strongly increasing the $\mathrm{H}$ dose $(d=34 \mathrm{KL})$ the NEXAFS spectrum closely resembles that of free standing graphene (bottom curve in Figure 6a). The vanishing intensity of the $\mathrm{C}-\mathrm{H}$ peak indicates that the hydrogen chemisorbed on graphene has been mostly released. The angular dependence of the spectra (Figure 6c) shows the strong dichroism and the sharp double structured $1 \mathrm{~s} \rightarrow \sigma^{*}$ resonance typical of non interacting graphene, clearly proving that graphene has been lifted due to $\mathrm{H}$ intercalation.

The results observed so far can be summarized as follows. Hydrogen chemisorption 
initiates as soon as the sample is exposed to the hydrogen flux and saturates quite rapidly. At larger exposures intercalation becomes evident. The intensity of the C1s components arising from hydrogenated graphene is transferred to $\mathrm{C}_{1}$, signaling the dissociation of $\mathrm{C}-\mathrm{H}$ bonds. This demonstrates that the chemisorbed $\mathrm{H}$ atoms are released and indirectly proves that the intercalated $\mathrm{H}$ atoms get adsorbed on the $\mathrm{Ni}$ surface rather than binding to the bottom side of graphene. ${ }^{18,19}$ Then a chemisorbed phase forms on the metal surface (the average $\mathrm{H}$ binding energy to $\mathrm{Ni}(111)$ varies in the range $2.9-1.4 \mathrm{eV}$, rapidly decreasing with increasing coverage). ${ }^{45,46}$

Determining how intercalation occurs at the atomic level is hard to assess at present, and it is beyond the aim of the present work. Penetration of Gr by hydrogen atoms can be confidently excluded since, in the absence of nanoscale openings, graphene is completely impermeable to thermal atoms and small molecules. ${ }^{47,48}$ Moreover, due to the large diffusion barrier of $\mathrm{H}$ on $\mathrm{Gr} / \mathrm{Ni}(111)$ and the ensuing scarce mobility of the adatoms, ${ }^{15}$ it is unlikely that at RT chemisorbed $\mathrm{H}$ atoms diffuse to lattice defects and intercalate below. However, abstraction processes on graphene are known to heat locally the substrate ${ }^{49}$ - because of the release of the puckering energy that is left on the substrate upon $\mathrm{H}_{2}$ molecule formation - and thus might contribute to enhance the adatom mobility. Furthermore, some surface diffusion is possible for non-thermal $\mathrm{H}$ adatoms that may form upon impact with graphene when the adsorption energy is efficiently channeled into translational energy along the surface, ${ }^{50,51}$ as it may happen when light projectiles impinge on corrugated surfaces. ${ }^{52}$ These hot-atom species, commonly found when $\mathrm{H}$ interact with bare metal surfaces, ${ }^{53}$ are able to travel for long distances from their formation point and can thus reach $\mathrm{Gr}$ defects and diffuse underneath graphene. The progressive occupation of the metal substrate sites by $\mathrm{H}$ adatoms relieves the strong $\mathrm{Gr} / \mathrm{Ni}$ interaction. Covering the whole Ni substrate is facilitated by the low diffusion barrier of the $\mathrm{H}$ adatoms on the metal surface, which has been calculated $(0.20 \mathrm{eV})^{31}$ to be only slightly higher than on the bare $\mathrm{Ni}(0.15 \mathrm{eV})$. Hence, since the saturation of the $\mathrm{Ni}$ surface prevents the stabilization of the $\mathrm{C}-\mathrm{H}$ bonds, the route to chemisorption on graphene 
becomes unfavorable, and the hydrogen content on top of Gr progressively vanishes because of the continuous abstraction process that unavoidably occurs during the exposure to the H-atom beam. A similar conversion from chemisorbed to intercalated $\mathrm{H}$ was observed for $\mathrm{BN} / \mathrm{Ni}(111) .^{22}$
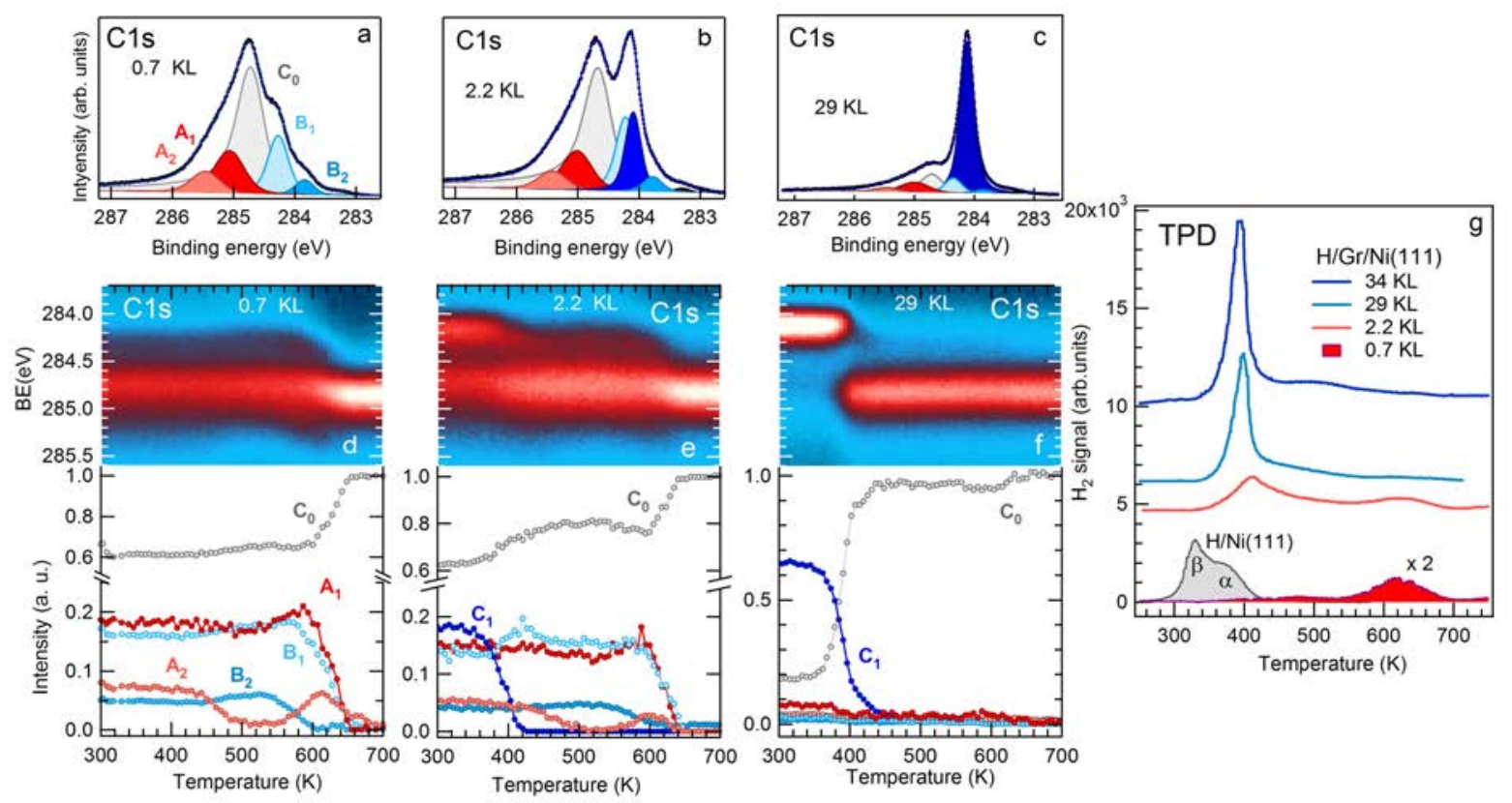

Figure 7: Thermal dehydrogenation of the $\mathrm{Gr} / \mathrm{Ni}(111)$ interface. a, b, c) C1s core level spectra measured on the $\mathrm{Gr} / \mathrm{Ni}(111)$ sample exposed to 0.7, 2.2 and $29 \mathrm{KL}$ of hydrogen (cfr. Figs. 1e, 1f and 1g). d, e, f) (top) 2D plots of the C1s intensity and (bottom) C1s component intensities measured during the thermal annealing of the samples shown in panels a, b and c, respectively. g) TPD $\mathrm{H}_{2}$ curves measured during the thermal annealing of the $\mathrm{Gr} / \mathrm{Ni}(111)$ sample exposed to selected hydrogen doses. The curves are vertically shifted for clarity. The filled red curve measured for $d=0.7 \mathrm{KL}$ is multiplied by a factor of 2 . The filled gray curve at the bottom was measured on the bare $\mathrm{Ni}(111)$ surface saturation-dosed with $\mathrm{H}_{2}$ at $130 \mathrm{~K}$. For the XPS measurements the heating rate was $0.5 \mathrm{~K} / \mathrm{s}$, whereas all TPD curves were measured with a heating rate of $2 \mathrm{~K} / \mathrm{s}$.

The thermal evolution of the different phases and the quantities of chemisorbed and intercalated $\mathrm{H}$ were determined by combining fast XPS and TPD measurements. Figures 7d, 7e and $7 \mathrm{f}$ show the $2 \mathrm{D}$ plots of the $\mathrm{C} 1 \mathrm{~s}$ intensity and the corresponding component intensities measured as a function of the temperature for the $\mathrm{Gr} / \mathrm{Ni}(111)$ sample dosed with $0.7,2.2$ and $29 \mathrm{KL}$. For ease of reading the corresponding C1s spectra measured in each case on 
the hydrogenated sample (cfr. Figures 1e-1g) are shown again in Figures 7a, 7b and 7c. Figure $7 \mathrm{~d}$ shows that, for the sample hydrogenated up to the saturation of the chemisorbed phase $(d=0.7 \mathrm{KL})$, the least thermally stable component is $\mathrm{A}_{2}$ (monomers and dimers), that at $\sim 450 \mathrm{~K}$ loses almost all its initial intensity. The decrease of $\mathrm{A}_{2}$ coincides with a slight increase of $\mathrm{C}_{0}$, indicating the occurrence of some desorption. Around $600 \mathrm{~K}$ hydrogen release is manifested by the increase of the $\mathrm{C}_{0}$ intensity. In concurrence with the strong reduction of the $\mathrm{H}$ coverage, the $\mathrm{A}_{2}$ component, that includes also the contribution of isolated $\mathrm{H}$ atoms, reappears. At $650 \mathrm{~K}$ the $\mathrm{H}$ desorption is complete since all $\mathrm{C} 1 \mathrm{~s}$ components have disappeared besides $\mathrm{C}_{0}$, that has recovered its pristine intensity. The perfect matching of the C1s spectra measured before hydrogenation and after desorption (see Figure S4) proves the reversibility of the process. For the sample dosed with $2.2 \mathrm{KL}$, in addition to the desorption of the chemisorbed $\mathrm{H}$, a partial restoration of the $\mathrm{C}_{0}$ intensity is triggered at $\sim 370 \mathrm{~K}$ by $\mathrm{H}$ deintercalation. For the highly hydrogenated sample $(d=29 \mathrm{KL})$, a sudden landing of almost the entire graphene layer occurs at $\sim 360 \mathrm{~K}$, due to the abrupt release of the high quantity of intercalated hydrogen. In this case the desorption of the residual chemisorbed $\mathrm{H}$ phase determines the recovery of the remaining $\sim 5 \%$ of the $\mathrm{C}_{0}$ intensity. The $\mathrm{C} 1 \mathrm{~s}$ spectrum measured on the de-intercalated graphene maintains the intensity of the pristine spectrum, but does not perfectly overlap with it, indicating the presence of small residual lifted regions, probably due to the presence of hydrogen atoms remained trapped underneath.

The hydrogen coverage at the different $\mathrm{H}$ doses was determined by acquiring the $\mathrm{H}_{2}$ TPD curves, that are shown, for selected cases, in Figure 7g. The amount of desorbing $\mathrm{H}_{2}$ was evaluated from the comparison with the TPD signal recorded for the bare $\mathrm{Ni}(111)$ surface saturation-dosed at low temperature $(130 \mathrm{~K})$ with $4 \mathrm{KL}$ of $\mathrm{H}_{2}$. In this case the TPD curve (filled gray) shows the $\alpha$ and $\beta$ maxima at 370 and $330 \mathrm{~K}$, whose intensity saturates at coverages of 0.5 and $1.0 \mathrm{ML}_{\mathrm{Ni}}$, respectively ${ }^{54,55}\left(1 \mathrm{ML}_{\mathrm{Ni}}=1.86 \times 10^{15}\right.$ atoms $/ \mathrm{cm}^{2}$ corresponds to the $\mathrm{Ni}(111)$ surface atomic density and to $0.5 \mathrm{ML}_{\mathrm{Gr}}$ ). Figure $7 \mathrm{~g}$ shows that the TPD curve (filled red) measured on the $\mathrm{Gr} / \mathrm{Ni}(111)$ sample dosed with $d=0.7 \mathrm{KL}$ exhibits only a weak 
and broad feature centered at $630 \mathrm{~K}$, counterpart of the $\mathrm{C}_{0}$ increase observed in the same temperature range in Figure 7a. The amount of desorbed $\mathrm{H}_{2}$ is equivalent to $\sim 0.16 \mathrm{ML}_{\mathrm{Gr}}$, a quantity that is in reasonable agreement with the $\mathrm{H}$ coverage of $0.20-0.25 \mathrm{ML}_{\mathrm{Gr}}$ determined with the analysis of the $\mathrm{C} 1 \mathrm{~s}$ spectrum. At higher $\mathrm{H}$ doses, the release of chemisorbed $\mathrm{H}$ at $630 \mathrm{~K}$ vanishes, while the peak due to the desorption of intercalated hydrogen appears at $\sim 400 \mathrm{~K},{ }^{20,22}$ and, with increasing $\mathrm{H}$ dose, gains intensity and slightly shifts to lower temperatures.

As for the total amount of desorbed $\mathrm{H}_{2}$, the sample exposed to 2.2, 29 and $34 \mathrm{KL}$ releases $0.56,0.83$ and $1.1 \mathrm{ML}_{\mathrm{Gr}}$, respectively. It is straightforward to notice that the amount of released $\mathrm{H}_{2}$ largely exceeds the quantity that can be adsorbed on the $\mathrm{Ni}(111)$ surface (saturation coverage $=1 \mathrm{ML}_{\mathrm{Ni}}=0.5 \mathrm{ML}_{\mathrm{Gr}}$ ). This evidence could be explained by assuming that some intercalated $\mathrm{H}$ atoms diffuse into the bulk of the Ni substrate. Actually, subsurface adsorption has been frequently observed for several metals, and in particular for $\mathrm{Ni}(111)^{55}$ and $\mathrm{Ni}(001)^{56}$ crystals exposed to atomic hydrogen at low temperature $(130 \mathrm{~K})$. This aspect deserves further investigation because the possibility that graphene might enable $\mathrm{H}$ diffusion in the underlaying $\mathrm{Ni}$ bulk at room temperature would open intriguing perspectives for energy storage.

\section{Conclusions}

The RT interaction of the $\mathrm{Gr} / \mathrm{Ni}(111)$ interface with $\mathrm{H}$ atoms leads to a dual path hydrogenation. At first $\mathrm{H}$ atoms chemisorb on the Gr surface up to a coverage of $0.20-0.25 \mathrm{ML}_{\mathrm{Gr}}$. The formation of $\mathrm{C}-\mathrm{H}$ bonds determines new components in the $\mathrm{C} 1$ s core level spectrum that are attributed by DFT calculations to $\mathrm{C}$ atoms directly bonded to $\mathrm{H}$ and to their first neighbors. STM images show that at low coverage $\mathrm{H}$ atoms predominantly adsorb as monomers in agreement with the calculations predicting a high stability for this arrangement on the Gr/Ni(111) surface. The progressive enlargement of H clusters revealed by the XPS spectra 
and the STM images is fully supported by the DFT results. In parallel, a slow but continuous intercalation is observed, which continues beyond the saturation of the chemisorpion on graphene and leads to the binding of $\mathrm{H}$ atoms at Ni surface sites. The chemisorbed hydrogen is released around $600 \mathrm{~K}$ whereas the intercalated phase desorbs abruptly slightly below $400 \mathrm{~K}$. Then the Gr cover, besides offering a storage volume for the intercalated H, stabilizes it above room temperature rising by a few tens of kelvins the $\mathrm{H}_{2}$ release temperature with respect to the bare $\mathrm{Ni}(111)$ surface. The effectiveness of these results can be expanded by using Ni substrates with large specific surface, as nanoparticles or nanostructured foils, which, when covered with graphene, might become media where hydrogen can be loaded and stored above room temperature.

\section{Methods}

The experiment was performed at the SuperESCA beamline of the synchrotron radiation source Elettra (Trieste, Italy). The Ni(111) crystal was mounted on a manipulator capable of providing fast-rate sample heating and cooling. The crystal was fixed to the cryostat by means of a Ta stick spotwelded on the back and was heated by W filaments placed behind the sample. Surface cleaning was carried out by repeated sputtering cycles at $1 \mathrm{KeV}$ followed by annealing up to $1020 \mathrm{~K}$. The sample quality was checked by means of low-energy electron diffraction (LEED) (see Figure S1) and by verifying that the spectral features relative to $\mathrm{C}$ and $\mathrm{O}$ contaminants were absent in the XPS spectra. Graphene was grown by dosing ethylene at $5 \times 10^{-7}$ mbar onto the $\mathrm{Ni}(111)$ surface kept at $890 \mathrm{~K}$. The complete coverage of the Ni substrate by the Gr monolayer was achieved by prolonging the exposure to ethylene well beyond the saturation of the layer growth, that was monitored on line by fast XPS spectroscopy of the C1s core level. The graphene layer was then exposed at room temperature to the hydrogen flux, at a pressure of $2 \times 10^{-6}$ mbar. During exposure $\mathrm{H}_{2}$ passed through a tungsten capillary at $T=3000 \mathrm{~K}$ to achieve thermal cracking. The cracker was positioned 
at a distance of $5 \mathrm{~cm}$ from the sample and was partially shuttered to prevent the sample from being directly exposed to the flux of $\mathrm{H}$ atoms and to the radiation emitted by the hot cracker filament. $\mathrm{H}$ atoms produced in the hot tube are estimated to have $0.25 \mathrm{eV}$ of kinetic energy. ${ }^{57}$ Even if it is reported that cracking efficiency of the $\mathrm{H}_{2}$ molecule at the used temperature is close to unity, ${ }^{13}$ we estimated that the fraction $f$ of dissociated molecules at the sample surface was in the range $0.7 \leq f \leq 0.9$. Due to the uncertainty on the $\mathrm{H} / \mathrm{H}_{2}$ ratio in the gas flux impinging on the sample, throughout this work data are plotted as a function of the total hydrogen dose $d$, as calculated from the pressure measured by the vacuum gauge, knowing that, since the dosing conditions were kept stable during the whole experiment, the atomic $\mathrm{H}$ is a fixed fraction $f$ of it. Hydrogen coverage on the Ni substrate or on graphene is given in monolayers, where $1 \mathrm{ML}_{\mathrm{Ni}}=1.86 \times 10^{15}$ atoms $/ \mathrm{cm}^{2}$, that is the atomic surface density of $\mathrm{Ni}(111)$ and $1 \mathrm{ML}_{\mathrm{Gr}}=2 \mathrm{ML}_{\mathrm{Ni}}$. High resolution $\mathrm{C} 1 \mathrm{~s}$ core level spectra were measured at a photon energy of $400 \mathrm{eV}$ whereas the VB spectra were measured at photon energy of $100 \mathrm{eV}$. In each case the overall energy resolution was below $50 \mathrm{meV}$. For each spectrum, the binding energy was calibrated by measuring the Fermi level position of the Ni substrate. The measurements were performed with the photon beam impinging at grazing incidence $\left(70^{\circ}\right)$, while photoelectrons were collected at normal emission angle. The core level spectra were best fitted with Doniach-S̆unjić functions convoluted with Gaussians, and a linear background. The C K-edge NEXAFS spectra were measured in the Auger yield mode by detecting the photoelectrons at a kinetic energy of $260 \mathrm{eV}$ corresponding to the CKLL transition, as a function of the angle $\theta$ between the electric field $E$ of the photon beam (which was horizontally polarized) and the normal to the substrate plane (or between the x-ray beam and the substrate plane). The angle $\theta$ was varied between $20^{\circ}$ (grazing incidence) and $90^{\circ}$ (normal incidence) by rotating the samples. STM measurements were carried out in the CoSMoS facility operating on the branch line of the SuperESCA beamline. Gr/Ni(111) samples were prepared in situ and hydrogenated as in the main SuperESCA end station, by using the same hydrogen cracker. By checking the hydrogenation by C1s spectroscopy 
we could prepare samples with the same $H$ coverage of those studied in the SuperESCA chamber. STM images were acquired at room temperature with a SPECS STM 150 Aarhus instrument equipped with a $\mathrm{W}$ tip. The TPD data were recorded with a quadrupole mass spectrometer equipped with a quartz shield ('Feulner cup'58) with a sample-size opening. Before each measurement, the sample was placed in front of the cup, almost in contact with it, and was heated with a rate of $2 \mathrm{~K} / \mathrm{s}$.

First-principles calculations were performed within the pseudopotential, spin-polarized density functional theory framework, as implemented in the periodic, atomic-orbital based SIESTA code, using the gradient-corrected exchange-correlation functional devised by Perdew, Burke and Ernzerhof ( $a k a$ PBE) to describe exchange and correlation effects. The KohnSham orbitals for the valence electrons ( $1 s$ for $\mathrm{H}, 2 s^{2} 2 p^{2}$ for $\mathrm{C}$ and $3 d^{8} 4 s^{2}$ for $\mathrm{Ni}$ ) were represented as linear combinations of numerical, atom-centered basis functions with compact support of double- $\zeta$ plus polarization quality whereas core electrons were replaced by norm-conserving pseudopotentials including partial core corrections. A $4 \times 4$ graphene layer was placed on top of a 5-layer $4 \times 4 \mathrm{Ni}$ slab, and several hydrogen clusters of different shape and size were considered on its outer surface. A large vacuum layer of ca. $9 \AA$, was introduced along the surface normal to avoid artificial interactions between periodic images and integrations over the Brillouin zone were carried out on a $\Gamma$-centered $4 \times 4 \times 1 k$-mesh following the Monkhorst-Pack scheme. A large cutoff was used for the real-space integrations (400 Ry) and structural optimizations were performed by relaxing atomic positions until the forces were smaller than $0.02 \mathrm{eV} / \AA$, keeping the three bottom layers of the Ni slab frozen to mimic the behavior of the bulk. Core-level shifts were computed for each carbon atom by performing single point calculations on the optimized structures using a modified pseudopotential for describing the core hole at the given site. Pseudoenergies differences (with and without the core hole) were computed and carefully compared to those obtained for pristine graphene, in order to obtain the CLS due to hydrogen adsorption. Supercell size was checked for convergence on the CLS calculations and found to be reasonably large to 
accommodate the core holes.

\section{Acknowledgements}

RL thanks Elettra-Sincrotrone Trieste for financial support.

\section{Supporting Information Available}

LEED pattern of $\mathrm{Gr} / \mathrm{Ni}(111)$. XPS spectroscopy of the Ni2p core level. C1s line shape. Reversibility of the hydrogenation-dehydrogenation cycle. C1s core level shifts and adsorption energies obtained by DFT calculations. This material is available free of charge via the Internet at http://pubs.acs.org.

\section{References}

1. Sofo, J. O.; Chaudhari, A. S.; Barber, G. D. Graphane: A Two-Dimensional Hydrocarbon. Phys. Rev. B 2007, 75, 153401.

2. Elias, D. C.; Nair, R. R.; Mohiuddin, T. M. G.; Morozov, S. V.; Blake, P.; Halsall, M. P.; Ferrari, A. C.; Boukhvalov, D. W.; Katsnelson, M. I.; Geim, A. K.; Novoselov, K. S. Control of Graphene's Properties by Reversible Hydrogenation: Evidence for Graphane. Science 2009, 323, 610-613.

3. Balog, R.; Jørgensen, B.; Nilsson, L.; Andersen, M.; Rienks, E.; Bianchi, M.; Fanetti, M.; Lægsgaard, E.; Baraldi, A.; Lizzit, S.; Sljivancanin, Z.; Besenbacher, F.; Hammer, B.; Pedersen, T. G.; Hofmann, P.; Hornekær, L. Bandgap Opening in Graphene Induced by Patterned Hydrogen Adsorption. Nat. Mater. 2010, 9, 315-319.

4. Castellanos-Gomez, A.; Wojtaszek, M.; Arramel,; Tombros, N.; van Wees, B. J. Re- 
versible Hydrogenation and Bandgap Opening of Graphene and Graphite Surfaces Probed by Scanning Tunneling Spectroscopy. Small 2012, 8, 1607-1613.

5. Balakrishnan, J.; Koon, G. K. W.; Jaiswal, M.; Neto, A. H. C.; Özyilmaz, B. Colossal Enhancement of Spin Orbit Coupling in Weakly Hydrogenated Graphene. Nat. Phys. 2013, 9, 284.

6. González-Herrero, H.; Gómez-Rodríguez, J. M.; Mallet, P.; Moaied, M.; Palacios, J. J.; Salgado, C.; Ugeda, M. M.; Veuillen, J.-Y.; Yndurain, F.; Brihuega, I. Atomic-Scale Control of Graphene Magnetism by Using Hydrogen Atoms. Science 2016, 352, 437441.

7. Bonfanti, M.; Achilli, S.; Martinazzo, R. Sticking of Atomic Hydrogen on Graphene. J. Phys. Condens. Matter 2018, 30, 283002.

8. Okamoto, Y.; Miyamoto, Y. Ab Initio Investigation of Physisorption of Molecular Hydrogen on Planar and Curved Graphenes. J. Phys. Chem. B 2001, 105, 3470-3474.

9. Tozzini, V.; Pellegrini, V. Prospects for Hydrogen Storage in Graphene. Phys. Chem. Chem. Phys. 2013, 15, 80-89.

10. Klechikov, A. G.; Mercier, G.; Merino, P.; Blanco, S.; Merino, C.; Talyzin, A. V. Hydrogen Storage in Bulk Graphene-Related Materials. Micropor. Mesopor. Mat. 2015, 210, $46-51$.

11. Klechikov, A.; Mercier, G.; Sharifi, T.; Baburin, I. A.; Seifert, G.; Talyzin, A. V. Hydrogen Storage in High Surface Area Graphene Scaffolds. Chem. Commun. 2015, 51, $15280-15283$.

12. Tozzini, V.; Pellegrini, V. Reversible Hydrogen Storage by Controlled Buckling of Graphene Layers. J. Phys. Chem. C 2011, 115, 25523-25528. 
13. Haberer, D.; Vyalikh, D.; Taioli, S.; Dora, B.; Farjam, M.; Fink, J.; Marchenko, D.; Pichler, T.; Ziegler, O. K.; Simonucci, S.; Dresselhaus, M. S.; Knupfer, M.; Büchner, B.; Grüneis A. Tunable Band Gap in Hydrogenated Quasi-Free-Standing Graphene. Nano Lett. 2010, 10, 3360-3366.

14. Ng, M. L.; Balog, R.; Hornekær, L.; Preobrajenski, A. B.; Vinogradov, N. A.; Märtensson, N.; Schulte, K. Controlling Hydrogenation of Graphene on Transition Metals. J. Phys. Chem. C 2010, 114, 18559.

15. Zhao, W.; Gebhardt, J.; Späth, F.; Gotterbarm, K.; Gleichweit, C.; Steinrück, H.-P.; Görling, A.; Papp, C. Reversible Hydrogenation of Graphene on Ni(111) - Synthesis of 'Graphone'. Chem. Eur. J. 2015, 21, 3347-3358.

16. Balog, R.; Andersen, M.; Jørgensen, B.; Sljivancanin, Z.; Hammer, B.; Baraldi, A.; Larciprete, R.; Hofmann, P.; Hornekær, L.; Lizzit, S. Controlling Hydrogenation of Graphene on $\operatorname{Ir}(111)$. ACS Nano 2013, 7, 3823-3832.

17. Jørgensen, J. H.; C̆abo, A. G.; Balog, R.; Kyhl, L.; Groves, M. N.; Cassidy, A. M.; Bruix, A.; Bianchi, M.; Dendzik, M.; Arman, M. A.; Lammich, L.; Pascual, J. I.; Knudsen, J.; Hammer, B.; Hofmann, P.; Hornekær L. Symmetry-Driven Band Gap Engineering in Hydrogen Functionalized Graphene. ACS Nano 2016, 10, 10798-10807.

18. Balgar, T.; Kim, H.; Hasselbrink, E. Preparation of Graphene with Graphane Areas of Controlled Hydrogen Isotope Composition on Opposite Sides. J. Phys. Chem. Lett. 2013, 4, 2094-2098.

19. Lin, C.; Feng, Y.; Xiao, Y.; Dürr, M.; Huang, X.; Xu, X.; Zhao, R.; Wang, E.; Li, X.-Z.; $\mathrm{Hu}, \mathrm{Z}$. Direct Observation of Ordered Configurations of Hydrogen Adatoms on Graphene. Nano Lett. 2015, 15, 903-908.

20. Brugger, T.; Ma, H.; Iannuzzi, M.; Berner, S.; Winkler, A.; Hutter, J.; Osterwalder, J.; 
Greber, T. Nanotexture Switching of Single-Layer Hexagonal Boron Nitride on Rhodium by Intercalation of Hydrogen Atoms. Angew. Chem. Int. Edit. 2010, 49, 6120-6124.

21. Wei, M.; Fu, Q.; Wu, H.; Dong, A.; Bao, X. Hydrogen Intercalation of Graphene and Boron Nitride Monolayers Grown on Pt(111). Top. Catal. 2016, 59, 543-549.

22. Späth, F.; Gebhardt, J.; Düll, F.; Bauer, U.; Bachmann, P.; Gleichweit, C.; Görling, A.; Steinrück, H.-P.; Papp, C. Hydrogenation and Hydrogen Intercalation of Hexagonal Boron Nitride on Ni(111): Reactivity and Electronic Structure. 2D Mater. 2017, 4, 035026 .

23. Rajasekaran, S.; Kaya, S.; Abild-Pedersen, F.; Anniyev, T.; Yang, F.; Stacchiola, D.; Ogasawara, H.; Nilsson, A. Reversible Graphene-Metal Contact through Hydrogenation. Phys. Rev. B 2012, 86, 075417.

24. Kyhl, L.; Bisson, R.; Balog, R.; Groves, M. N.; Kolsbjerg, E. L.; Cassidy, A. M.; Jørgensen, J. H.; Halkjær, S.; Miwa, J. A.; C̆abo, A. G.; Angot, T.; Hofmann, P.; Arman, M. A.; Urpelainen, S.; Lacovig, P.; Bignardi, L.; Bluhm, H.; Knudsen, J.; Hammer, B.; Hornekær, L. Exciting $\mathrm{H}_{2}$ Molecules for Graphene Functionalization. ACS Nano 2018, 12, 513-520.

25. Iwasaki, T.; Park, H. J.; Konuma, M.; Lee, D. S.; Smet, J. H.; Starke, U. Long-Range Ordered Single-Crystal Graphene on High-Quality Heteroepitaxial Ni Thin Films Grown on $\mathrm{MgO}(111)$. Nano Letters 2011, 11, 79-84.

26. Zhao, W.; Kozlov, S. M.; Hofert, O.; Gotterbarm, K.; Lorenz, M. P. A.; nes, F. V.; C.Papp,; Görling, A.; Steinrück, H.-P. Graphene on Ni(111): Coexistence of Different Surface Structures. J. Phys. Chem. Lett. 2011, 2, 759-764.

27. Soni, H. R.; Gebhardt, J.; Görling, A. The Reactivity of Substrate-Supported Graphene: A Case Study of Hydrogenation. J. Phys. Chem. C 2018, 122, 2761-2772. 
28. Bahn, E.; Tamtögl, A.; Ellis, J.; Allison, W.; Fouquet, P. Structure and Dynamics Investigations of a Partially Hydrogenated Graphene/Ni(111) Surface. Carbon 2017, $114,504-510$.

29. Politano, A.; Cattelan, M.; Boukhvalov, D. W.; Campi, D.; Cupolillo, A.; Agnoli, S.; Apostol, N. G.; Lacovig, P.; Lizzit, S.; Farías, D.; Chiarello, G.; Granozzi, G.; Larciprete, R. Unveiling the Mechanisms Leading to $\mathrm{H}_{2}$ Production Promoted by Water Decomposition on Epitaxial Graphene at Room Temperature. ACS Nano 2016, 10, 4543-4549.

30. Zhou, C.; Szpunar, J. A.; Cui, X. Synthesis of Ni/Graphene Nanocomposite for Hydrogen Storage. ACS Appl. Mater. Interfaces 2016, 8, 15232-15241.

31. Zhou, Y.; Chen, W.; Cui, P.; Zeng, J.; Lin, Z.; Kaxiras, E.; Zhang, Z. Enhancing the Hydrogen Activation Reactivity of Nonprecious Metal Substrates via Confined Catalysis Underneath Graphene. Nano Lett. 2016, 16, 6058-6063.

32. Liu, Y.; Zhang, Z.; Wang, T. Enhanced Hydrogen Storage Performance of ThreeDimensional Hierarchical Porous Graphene with Nickel Nanoparticles. Int. J. Hydrog. Energy 2018, 43, 11120-11131.

33. Balog, R.; Jørgensen, B.; Wells, J.; Lægsgaard, E.; Hofmann, P.; Besenbacher, F.; Hornekær, L. Atomic Hydrogen Adsorbate Structures on Graphene. J. Amer. Chem. Soc. 2009, 131, 8744-8745.

34. Merino, P.; Švec, M.; Martínez, J. I.; Mutombo, P.; Gonzalez, C.; Martín-Gago, J. A.; de Andres, P. L.; Jelinek, P. Ortho and Para Hydrogen Dimers on G/SiC(0001): Combined STM and DFT Study. Langmuir 2015, 31, 233-239.

35. Pizzochero, M.; Bonfanti, M.; Martinazzo, R. Hydrogen on Silicene: like or unlike Graphene? Phys. Chem. Chem. Phys. 2016, 18, 15654-15666. 
36. Hornekær, L.; Šljivančanin, v.; Xu, W.; Otero, R.; Rauls, E.; Stensgaard, I.; Lægsgaard, E.; Hammer, B.; Besenbacher, F. Metastable Structures and Recombination Pathways for Atomic Hydrogen on the Graphite (0001) Surface. Phys. Rev. Lett. 2006, 96, 156104.

37. Larciprete, R.; Colonna, S.; Ronci, F.; Flammini, R.; Lacovig, P.; Apostol, N.; Politano, A.; Feulner, P.; Menzel, D.; Lizzit, S. Self-Assembly of Graphene Nanoblisters Sealed to a Bare Metal Surface. Nano Lett. 2016, 16, 1808-1817.

38. Bignardi, L.; Lacovig, P.; Dalmiglio, M. M.; Orlando, F.; Ghafari, A.; Petaccia, L.; Baraldi, A.; Larciprete, R.; Lizzit, S. Key Role of Rotated Domains in Oxygen Intercalation at Graphene on $\mathrm{Ni}(111)$. 2D Mater. 2017, 4, 025106.

39. Granäs, E.; Gerber, T.; Schröder, U. A.; Schulte, K.; Andersen, J. N.; Michely, T.; Knudsen, J. Hydrogen Intercalation under Graphene on $\operatorname{Ir}(111)$. Surf. Sci. 2016, 651, $57-61$.

40. Varykhalov, A.; Sánchez-Barriga, J.; Shikin, A. M.; Biswas, C.; Vescovo, E.; Rybkin, A.; Marchenko, D.; Rader, O. Electronic and Magnetic Properties of Quasifreestanding Graphene on Ni. Phys. Rev. Lett. 2008, 101, 157601.

41. Stör, J. NEXAFS Spectroscopy; Springer, Berlin, 1992.

42. Weser, M.; Rehder, Y.; Horn, K.; Sicot, M.; Fonin, M.; Preobrajenski, A. B.; Voloshina, E. N.; Goering, E.; Dedkov, Y. S. Induced Magnetism of Carbon Atoms at the Graphene/Ni(111) Interface. Appl. Phys. Lett. 2010, 96, 012504.

43. Rajasekaran, S.; Kaya, S.; Abild-Pedersen, F.; Anniyev, T.; Yang, F.; Stacchiola, D.; Ogasawara, H.; Nilsson, A. Reversible Ggraphene-Metal Contact through Hydrogenation. Phys. Rev. B 2012, 86, 075417. 
44. Xie, L.; Wang, X.; Lu, J.; Ni, Z.; Luo, Z.; Mao, H.; Wang, R.; Wang, Y.; Huang, H.; Qi, D.; Liu, R.; Yu, T.; Shen, S.; Wu, T.; Peng, H.; Özyilmaz, B.; Loh, K.; Wee, A. T. S.; Ariando; Chen, W. Room Temperature Ferromagnetism in Partially Hydrogenated Epitaxial Graphene. Appl. Phys. Lett. 2011, 98, 193113.

45. Ferrin, P.; Kandoi, S.; Nilekar, A. U.; Mavrikakis, M. Hydrogen Adsorption, Absorption and Diffusion on and in Transition Metal Surfaces: A DFT Study. Surf. Sci. 2012, 606, 679-689.

46. Shirazi, M.; Bogaerts, A.; Neyts, E. C. A DFT Study of H-Dissolution into the Bulk of a Crystalline Ni(111) Surface: a Chemical Identifier for the Reaction Kinetics. Phys. Chem. Chem. Phys. 2017, 19, 19150-19158.

47. Bunch, J. S.; Verbridge, S. S.; Alden, J. S.; van der Zande, A. M.; Parpia, J. M.; Craighead, H. G.; McEuen, P. L. Impermeable Atomic Membranes from Graphene Sheets. Nano Lett. 2008, 8, 2458-2462.

48. Miao, M.; Buongiorno Nardelli, M.; Wang, Q.; Liu, Y. First Principles Study of the Permeability of Graphene to Hydrogen Atoms. Phys. Chem. Chem. Phys. 2013, 15, $16132-16137$.

49. Pasquini, M.; Bonfanti, M.; Martinazzo, R. Full Quantum Dynamical Investigation of the Eley-Rideal Reaction Forming $\mathrm{H}_{2}$ on a Movable Graphitic Substrate at $\mathrm{T}=0 \mathrm{~K}$. Phys. Chem. Chem. Phys. 2018, 20, 977-988.

50. Satta, M.; Lacovig, P.; Apostol, N.; Dalmiglio, M.; Orlando, F.; Bignardi, L.; Bana, H.; Travaglia, E.; Baraldi, A.; Lizzit, S.; Larciprete, R. The Adsorption of Silicon on an Iridium Surface Ruling out Silicene Growth. Nanoscale 2018, 10, 7085-7094.

51. Satta, M.; Colonna, S.; Flammini, R.; Cricenti, A.; Ronci, F. Silicon Reactivity at the Ag(111) Surface. Phys. Rev. Lett. 2015, 115, 026102. 
52. Bonfanti, M.; Martinazzo, R. Classical and Quantum Dynamics at Surfaces: Basic Concepts from Simple Models. Int. J. Quantum Chem. 116, 1575-1602.

53. Harris, J.; Kasemo, B. On Precursor Mechanisms for Surface Reactions. Surf. Sci. 1981, 105, L281-L287.

54. Christmann, K.; Behm, R. J.; Ertl, G.; Van Hove, M. A.; Weinberg, W. H. Chemisorption Geometry of Hydrogen on Ni(111): Order and Disorder. J. Chem. Phys. 1979, 70, 4168.

55. Johnson, A. D.; Maynard, K. J.; Daley, S. P.; Yang, Q. Y.; Ceyer, S. T. Hydrogen Embedded in Ni: Production by Incident Atomic Hydrogen and Detection by HighResolution Electron Energy Loss. Phys. Rev. Lett. 1991, 67, 927-930.

56. Kammler, T.; Wehner, S.; Küpper, J. Interaction of Thermal H Atoms with Ni(100)-H Surfaces: through Surface Penetration and Adsorbed Hydrogen Abstraction. Surf. Sci. 1995, 339, 125-134.

57. Aréou, E.; Cartry, G.; Layet, J.-M.; Angot, T. Hydrogen-Graphite Interaction: Experimental Evidences of an Adsorption Barrier. J. Chem. Phys. 2011, 134, 014701.

58. Feulner, P.; Menzel, D. Simple Ways to Improve Flash Desorption Measurements from Single Crystal Surfaces. J. Vac. Sci. Technol. 1980, 17, 662-663. 

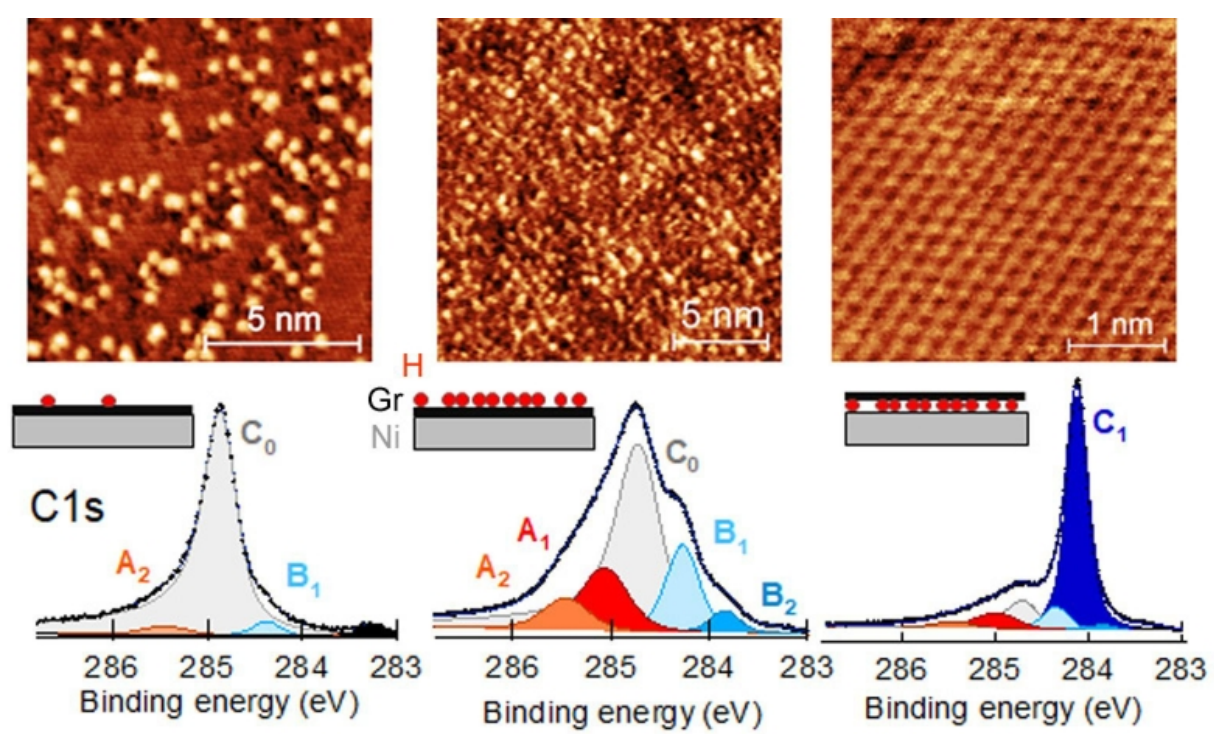

$70 \times 39 \mathrm{~mm}(300 \times 300 \mathrm{DPI})$ 